\title{
Comparing warm compresses application vs. chilled cabbage leaves for relieving breast engorgement among post-natal mothers
}

\author{
Hayam Fathey Ahmed Eittah ${ }^{* 1,2}$, Eman Seif S. Ashour ${ }^{1}$ \\ ${ }^{1}$ Maternal and Newborn Health Nursing, Faculty of Nursing, Menoufia University, Egypt \\ ${ }^{2}$ Maternal and Newborn Health Nursing, Nursing College, Taibah University, Al Madina Al Monwarrah, Kingdom of Saudi Arabia
}

Received: April 9, 2019

DOI: $10.5430 /$ cns.v7n3p58
Accepted: June 12, 2019

URL: https://doi.org/10.5430/cns.v7n3p58

Online Published: July 1, 2019

\begin{abstract}
Background: Breast engorgement is a common problem among postnatal women worldwide, some of whom use warm compresses to promote vasodilatation, improve circulation, and promote the amount of milk produced by the breasts. Conversely, the application of chilled cabbage leaves can reduce pain, the firmness of the engorged breasts, and prolong breastfeeding duration. Purpose: To examine the effect of warm compresses application as compared to chilled cabbage leaves for relieving breast engorgement and pain.

Methods: Setting: The study was carried out at a postnatal ward and outpatient clinic at two hospitals in Menoufia Governorate, Egypt. Sampling: Simple randomization technique was used to divide 100 post-natal women into two groups who received intervention with warm compresses (Group 1) and chilled cabbage leaves (Group 2). Instruments: Instrument I: interviewing questionnaire; Instrument II: six-points breast engorgement scale; and Instrument III: visual analog scale (VAS).

Results: There was a highly statistically significant difference and improvement in terms of reduced engorgement and pain degree for both groups, with greater improvement was observed in Group 2 when compared to Group 1.

Conclusions: Chilled cabbage leaves are effective in the treatment of breast engorgement and pain than warm compresses.

Recommendations: The mothers should be advised to use chilled cabbage leaves as a home remedy to minimize breast engorment and promote comfort, further studies are recommended in this area in order to expand the evidence based approaches on management of breast engorgement.
\end{abstract}

Key Words: Warm compresses application, Chilled cabbage leaves, Breast engorgement, Post-natal

\section{INTRODUCTION}

Postpartum period is the time that starts right after birth and extends for about six weeks. Postpartum care's main focus is to ensure that the mother is healthy and, equipped with all the information she needs about breast feeding, reproductive health, contraception, and adjustment to life. ${ }^{[1]}$ Breast engorgement is a problem for many lactating women that must be addressed in the client care. It is a painful overfilling of the breast with milk, which is a physiological unpleasant condition that can cause great distress among mothers, feeding and attachment issues. It is usually associated with acute pain, swelling, tenderness and redness of the nipple that may lead to breast feeding cessation. The engorgement is charac-

${ }^{*}$ Correspondence: Hayam Fathey Ahmed Eittah; Email: hayameittah@yahoo.com; Address: Maternal and Newborn Health Nursing, Faculty of Nursing, Menoufia University, Egypt. 
terized by shining appearance of the breast, firmness of the breast, mild to severe fever and unpleasant discomfort. ${ }^{[2]}$ It is caused by venous congestion of the breast, subsequently compounded by the pressure of milk. It can be extremely painful. ${ }^{[3,4]}$

Breast pain during breastfeeding is a common problem that interferes with successful breastfeeding and may lead to premature weaning. ${ }^{[5,6]}$ Breast engorgement may affect the area around the nipple and areola only, or the entire breast, and may affect one breast only, or both. Once engorgement occurs, swelling around the nipple may make it even more difficult for the newborn to latch-on and feed successfully, and make the engorgement worse. However, women may also receive limited advice and support from the health professionals; a lack of knowledge in managing this condition could be the reason for limited or inappropriate advice. ${ }^{[7]}$

Managing breast engorgement has always been a challenge for clinicians working with postnatal mothers. Many pharmacological and non-pharmaceutical methods for the treatment of breast engorgement have been explored. Many nonpharmacological interventions are used to relieve breast engorgement, including the application of warm compresses and chilled cabbage leaves directly to the breast. Both are natural ways of treating and reducing the maternal morbidity and help to improve lactation. ${ }^{[8]}$ The most common way to administer a warm compress is using a hand towel or sponge cloth dampened with warm water on the breasts just before the mother feeds, commonly done to stimulate milk flow due to vasodilatation. ${ }^{[9,10]}$ It enhances vasodilatation, facilitates blood flow, and increases the milk production by the breasts. Using compresses of chilled cabbage leaves are effective for engorgement therapy, reducing swelling in moderate to severe engorgement. It has been suggested that this may be related to the chemical sinigrin, which is absorbed through the mother's skin, that may reduce edema and increase milk flow. ${ }^{[11]}$ In addition, cabbage identified that contains mustard oil, magnesium, oxylate and sulphurheterosidesn and has antibiotic and anti-inflammatory properties. ${ }^{[7]}$ It improves the blood flow in and out of the area, allowing the body to reabsorb the fluid trapped in the breasts. Chilled cabbage leaves compresses should not be used if the skin is broken or cracked, or if the nipples are blistered. If the skin is broken, the chilled cabbage leaves may be placed around the breast, without covering the irritated skin, as they contain sulpha, which causes irritation. ${ }^{[5]}$ It was important for the clinicians to know the clinical guidelines for the management of breast engorgement with warm compresses versus chilled cabbage leaves approach to provide evidence based practice for introducing this intervention in the clinical practice field. The clinicians should concentrate on prevention of

Published by Sciedu Press breast engorgement by providing counseling to the mother about starting breastfeeding as soon as possible after the birth, to give the newborn time to learn to breastfeed before the breasts become full and firm, avoid early use of bottles. Once the milk comes in the mother should breastfeed at least eight times in 24 hours to prevent over fullness and use hand expression or a breast pump to remove the remaining milk. Also, early postpartum care is necessary to diagnose and treat complications. ${ }^{[12-14]}$

\subsection{Purpose of the study}

To examine the effect of warm compresses application as compared to chilled cabbage leaves for relieving breast engorgement and pain.

\subsection{Research hypothesis}

Chilled cabbage leaves are more effective than warm compresses application to relieve breast engorgement and pain among postnatal mothers.

\section{SUBJECT AND METHODS}

\subsection{Research design}

A randomized clinical trial research design was utilized in this research with pretest-posttest design, two groups of subjects observed before and after the intervention.

\subsection{Setting}

The study was carried out at a postnatal ward and outpatient clinic at two hospitals in Menoufia Governorate, Egypt; the cases were recruited in this study from these hospitals, then they were followed up by home visits to complete the course of the intervention. There is high flow rate of mothers who attend these hospitals from the different surrounding cities and villages. The flow rate of delivery cases is about five thousand women annually.

The first hospital has a key role in undergraduate education for health care professionals. It provides free and paid services during pregnancy, labor, postpartum, and miscarriage. As well as infertility treatment and gynecological care for public clients.

The second hospital is affiliated to the Ministry of Health and Population. It provides similar free and paid services to public clients and care services for women during pregnancy and labor, as well as for infertility and gynecological problems, in addition to family planning services.

\subsection{Sampling}

A total of 100 postnatal mothers were recruited according to the following inclusion criteria. Postnatal mothers who delivered 4-6 days ago, complained from breast engorgement, 
normal vaginal delivery, agreed to participate voluntarily in the study and had no allergy to sulpha. While the exclusion criteria were mothers with allergy to sulpha, mothers with allergy to cabbage, cesarean delivery, mothers received lactation suppressants, mothers with infection in the breasts, breast abscess, mastitis, broken skin of breasts, bleeding or cracked nipples and mothers received pain medications.

Sample size calculation: The sample was calculated using the sample size calculator with confidence level 10, population was 50,000. The total sample was 96 and it was increased to 100 to ensure representativeness. The cases were then randomly assigned (using simple random technique) into two groups, by asking each of the 100 women to pick a piece of paper containing a number; those who selected number $1(\mathrm{n}=50)$ were assigned to Group 1 (warm compresses), and those who selected number $2(\mathrm{n}=50)$ were assigned to Group 2 (chilled cabbage leaves). This technique used to avoid sample contamination and bias.

\subsection{Instruments}

Instrument I: Structured interviewing questionnaire: The researchers developed the questionnaire after extensive reviewing of literature. It included two sections: the first section contained personal and demographic data of post-natal mothers, medical and obstetric history; and the second included data which related to the nipple and breast condition, the interviewing questionnaire was in simple Arabic language.

Instrument II: Six-points engorgement scale: The scale was used to evaluate the scores of breast engorgement and measuring the mothers' perception of breast engorgement changes, given score ranging from one to six. It was adopted from Hill and Humenick. ${ }^{[15]}$

According to the assessment performed by the researchers, women were given scores of: (1) for soft and no changes in the breast; (2) for slight changes in the breast; (3) for firm and no tender breast; (4) for firm; and beginning tenderness in the breast; score of (5) for firm and tender breast; and (6) for very firm and very tender.

Instrument III: Visual analog scale (VAS): It is a simple and frequently used tool for the assessment of variations in intensity of pain, this was adopted from Gift. ${ }^{[16]}$ In clinical practice the percentage of pain relief assessed by VAS, is often considered as a measure of the efficacy of intervention. To facilitate the scoring and measurement, a $10 \mathrm{~cm}$ line is usually used, ranging from zero that mean "no pain" to 10 that means "severe pain", whereas the postnatal mothers were asked to place a mark on the line that describe the pain being experienced. The VAS is divided into three portions: 1-3 $\mathrm{cm}$ reflects mild pain, $4-7 \mathrm{~cm}$ moderate pain, and 8-10 cm severe/ worst pain.

\subsection{Validity and reliability}

For validity purposes the researchers conducted an extensive literature review and developed the questionnaire from previously used tools and reviewing pertinent reviews. Tool I was designed by the researchers and revised by five experts in the field of maternal and newborn health nursing in the Faculty of Nursing of Menoufia University (for content validity), while tools II and III were adopted from previous studies. The interviewing questionnaire underwent some modifications according to the panel judgment regarding the clarity of sentences and appropriateness of content. Test-retest reliability was used to estimate reliability for tool I. Cronbach's Alpha coefficient test was used to estimate reliability for tools II and III (results 0.73 ) which revealed that each of the two tools consisted of relatively homogenous items as indicated by the moderate to high reliability of each instrument.

Formula of Cronbach's alpha (see Equation 1):

$$
\alpha=\frac{N \cdot \bar{c}}{\bar{v}+(N-1) \cdot \bar{c}}
$$

$N=$ the number of items.

$\bar{c}=$ average covariance between item-pairs.

$\bar{v}=$ average variance.

\subsection{Pilot study}

The questionnaire was applied to $10 \%$ of the sample (10 mothers) taken from the postnatal ward and outpatient clinic to assess the feasibility, applicability, clarity and simplicity of the items and the maneuver of the intervention, and to estimate the time needed to answer them. According to its results; the final version of the tools was prepared. This also helped in planning the schedule for field work.

\subsection{Ethical consideration}

A primary approval was obtained from the Ethical research committee of Faculty of Nursing, Menoufia University before conducting the study. As well as a written letter from Faculty of Nursing Menoufia University was directed to the heads of the departments of gynecology and obstetrics in the study settings before starting the data collection. A written informed consent was taken from all women before enrolling them in the study after explaining the purpose of the study. The women were informed that their participation in the study was voluntary and they could withdraw from the study whenever they decide. Confidentiality was achieved by the use of locked sheets with the names of the participated women replaced by numbers. The women were informed that the information they provided during the study would be kept confident and used only for statistical purpose after finishing 
the study.

\subsection{Procedure}

The collection of data took about six months, from the beginning of October 2017 to the end of February 2018 from the postnatal ward and outpatient clinic from 8 am to $1 \mathrm{pm}$ for four days per week. The collection of data passed by 3 stages: interviewing and assessment stage, implementation, and evaluation.

\subsection{Interview and assessment}

In this stage the postnatal mothers were recruited based on the inclusion and exclusion criteria. the sociodemographic data and obstetrical history of each mother were documented. This phase took about 20 minutes for each mother. The mothers were asked questions in a simple Arabic language and their answers were recorded in the instruments used. Each woman was assessed thoroughly by taking her personal history, past history, present obstetrical history, then assessing the nipple type/condition (normal, flat, inverted, or cracked). The condition of each breast and degree of engorgement was then determined using the six-points engorgement scale, which gives points from 0 to 6 according to the degree of engorgement, then the pain was assessed for each mother by using visual analogue scale, scored on a scale from 0 to 10 , as explained previously.

\subsection{Implementation}

During this phase, the mothers were randomly assigned into two groups of 50 mothers each, with Group 1 receiving warm compresses and Group 2 receiving chilled cabbage leaves in order to reduce breast engorgement.

Group 1 received warm moist sponge cloth compresses applied to the engorged breasts; the sponge was replaced frequently every two minutes for about twenty minutes. The temperature of the water for warm compresses ranged between $109.4-114.4^{\circ} \mathrm{F}\left(43^{\circ} \mathrm{C}\right.$ to $\left.46^{\circ} \mathrm{C}\right)$, as determined by a thermometer.

Group 2 received chilled cabbage leaves. Cabbage leaves were rinsed carefully by water then chilled before use. A small piece of chilled cabbage leaf placed on the skin of postnatal mother to test sensitivity before starting the intervention. Cabbage leaves were cooled in the freezer for about thirty minutes before application. Chilled cabbage leaves were applied directly to the engorged breasts for 15-20 minutes, the mother can wear it inside her brassiere. Wilted leaves were then removed, and replaced by fresh one.
Both the interventions were performed three times a day for two continuous days for each participant; thus each intervention method was applied six times for each mother. The duration of each intervention was 15-20 minutes.

\subsection{Evaluation}

The pre- and post-treatment scores of breast engorgement and pain were recorded before and after each treatment session. Breast engorgement was measured using six-points breast engorgement scale for each group and the pain score was assessed using visual analogue scale. The scores of engorgement and pain are compared between hot compresses group and chilled cabbage leaves group.

\subsection{Data analysis}

The assembled data recorded, tabulated and analyzed using SPSS version 20. Descriptive as well as parametric inferential statistics were utilized to analyze data of the study. The level of significance was set at $p<.05$. Chi-square test, independent sample $t$-test, repeated measures ANOVA, Mean and Bonferroni Post hoc test were used to analyze the data.

\section{RESULTS}

Table 1 shows the socio-demographic characteristics of the study participants. There were no statistically significant differences between the study participants regarding age and level of education $(p \geq .05)$.

Table 2 displays the obstetrical history and condition of the mothers' nipples. It can be seen that there is no statistically significant difference between the study participants regarding parity, nipple condition and type of delivery. The majority of the study participants (62\%) were primiparous. Regarding the type of nipple, approximately half $(52 \%)$ had normal nipples, while others had nipple problems such as inverted, sore, and flat nipples $(17 \%, 13 \%$, and $18 \%$, respectively).

Table 3 shows the engorgement scale among the group 1 (warm compresses) and Group 2 (Chilled Cabbage Leaves). It can be seen that there is a great improvement in the degree of engorgement after the intervention compared to before the intervention, the most improvement was observed in group 2 when compared to group 1, with a highly statistically significant difference $(p \geq .001)$. Almost half of sample (48\%) of group 1 and $48 \%$ of group 2 complained from very firm hard and tender breasts according to engorgement scale (6 scores). But after treatment $30 \%$ of women in group 1 take score 1 (soft breast) this compared to $54 \%$ of group 2 who take score 1 (soft breast). 
Table 1. Socio-demographic characteristics of the study participants $(n=100)$

\begin{tabular}{|c|c|c|c|c|c|c|}
\hline Variables & & $\begin{array}{c}\text { Group } 2(n=50) \\
\text { (warm compresses) }\end{array}$ & $\begin{array}{c}\text { Group } 1(\mathrm{n}=50) \\
\text { (chilled cabbage leaves) }\end{array}$ & Total & $\chi^{2}$ & $p$-value \\
\hline \multicolumn{7}{|l|}{ Age (years) } \\
\hline \multirow[t]{2}{*}{$20-24$} & No. & 14 & 11 & 25 & \multirow{8}{*}{2.509} & \multirow{8}{*}{.474} \\
\hline & $\%$ & $28.0 \%$ & $22.0 \%$ & $25.0 \%$ & & \\
\hline \multirow[t]{2}{*}{$25-28$} & No. & 15 & 17 & 32 & & \\
\hline & $\%$ & $30.0 \%$ & $34.0 \%$ & $32.0 \%$ & & \\
\hline \multirow[t]{2}{*}{$29-32$} & No. & 21 & 20 & 41 & & \\
\hline & $\%$ & $42.0 \%$ & $40.0 \%$ & $41.0 \%$ & & \\
\hline \multirow[t]{2}{*}{$33-36$} & No. & 0 & 2 & 2 & & \\
\hline & $\%$ & $0.0 \%$ & $4.0 \%$ & $2.0 \%$ & & \\
\hline \multicolumn{7}{|c|}{ Marital status } \\
\hline Married & $\begin{array}{l}\text { No. } \\
\%\end{array}$ & $\begin{array}{c}50 \\
100.0 \%\end{array}$ & $\begin{array}{c}50 \\
100.0 \%\end{array}$ & $\begin{array}{c}100 \\
100.0 \%\end{array}$ & - & - \\
\hline \multicolumn{7}{|l|}{ Education } \\
\hline \multirow[t]{2}{*}{ Diploma } & No. & 10 & 8 & 18 & \multirow{6}{*}{2.33} & \multirow{6}{*}{.36} \\
\hline & $\%$ & $20.0 \%$ & $16.0 \%$ & $18.0 \%$ & & \\
\hline \multirow[t]{2}{*}{ Bachelor's } & No. & 35 & 36 & 71 & & \\
\hline & $\%$ & $70.0 \%$ & $72.0 \%$ & $71.0 \%$ & & \\
\hline \multirow[t]{2}{*}{ Postgraduate } & No. & 5 & 6 & 11 & & \\
\hline & $\%$ & $10.0 \%$ & $12.0 \%$ & $11.0 \%$ & & \\
\hline
\end{tabular}

Table 2. Obstetrical history and nipple condition of the study participants $(n=100)$

\begin{tabular}{|c|c|c|c|c|c|c|}
\hline \multicolumn{2}{|l|}{ Variables } & Group $1(n=50)$ & Group $2(n=50)$ & Total & $\chi^{2}$ & $p$-value \\
\hline \multicolumn{7}{|l|}{ Parity } \\
\hline Primi-para & No. & 34 & 28 & 62 & \multirow{4}{*}{1.528} & \multirow{4}{*}{.216} \\
\hline \multirow{3}{*}{ Multi-para } & $\%$ & $68.0 \%$ & $56.0 \%$ & $62.0 \%$ & & \\
\hline & No. & 16 & 22 & 38 & & \\
\hline & $\%$ & $32.0 \%$ & $44.0 \%$ & $38.0 \%$ & & \\
\hline \multicolumn{7}{|c|}{ Type of delivery } \\
\hline \multirow{2}{*}{$\begin{array}{l}\text { Normal } \\
\text { vaginal }\end{array}$} & No. & 50 & 50 & 100 & \multirow{2}{*}{-} & \multirow{2}{*}{ - } \\
\hline & $\%$ & $100.0 \%$ & $100.0 \%$ & $100.0 \%$ & & \\
\hline \multicolumn{7}{|c|}{ Type of nipple } \\
\hline \multirow[t]{2}{*}{ Inverted } & No. & 13 & 4 & 17 & \multirow{8}{*}{14.987} & \multirow{8}{*}{.002} \\
\hline & $\%$ & $26.0 \%$ & $8.0 \%$ & $17.0 \%$ & & \\
\hline \multirow[t]{2}{*}{ Sore } & No. & 10 & 3 & 13 & & \\
\hline & $\%$ & $20.0 \%$ & $6.0 \%$ & $13.0 \%$ & & \\
\hline \multirow[t]{2}{*}{ Flat } & No. & 10 & 8 & 18 & & \\
\hline & $\%$ & $20.0 \%$ & $16.0 \%$ & $18.0 \%$ & & \\
\hline \multirow[t]{2}{*}{ Normal } & No. & 17 & 35 & 52 & & \\
\hline & $\%$ & $34.0 \%$ & $70.0 \%$ & $52.0 \%$ & & \\
\hline
\end{tabular}


Table 3. Longitudinal engorgement scale in Group 1 and Group 2 (warm compresses \& chilled cabbage leaves)

\begin{tabular}{|c|c|c|c|c|c|c|c|c|c|c|c|c|c|c|c|}
\hline & \multicolumn{15}{|c|}{ Application } \\
\hline & \multicolumn{2}{|c|}{ 0 } & \multicolumn{2}{|c|}{1} & \multicolumn{3}{|c|}{2} & \multicolumn{2}{|c|}{3} & \multicolumn{2}{|c|}{4} & \multicolumn{2}{|c|}{5} & \multicolumn{2}{|c|}{6} \\
\hline & G1 & G2 & G1 & G2 & G1 & G2 & & G1 & G2 & G1 & G2 & G1 & G2 & G1 & G2 \\
\hline \multirow[t]{2}{*}{$\mathrm{A}$} & 0 & 0 & 0 & 0 & 0 & 0 & & 0 & 0 & 0 & 0 & 0 & 0 & 15 & 27 \\
\hline & $0 \%$ & $0.0 \%$ & $0.0 \%$ & $0.0 \%$ & $0.0 \%$ & $0.0 \%$ & & $0.0 \%$ & $0.0 \%$ & $0.0 \%$ & $0.0 \%$ & $0.0 \%$ & $0.0 \%$ & $30 \%$ & $54 \%$ \\
\hline \multirow[t]{2}{*}{ B } & 0 & 0 & 0 & 0 & 0 & 0 & & 0 & 0 & 0 & 0 & 3 & 6 & 17 & 15 \\
\hline & $0.0 \%$ & $0.0 \%$ & $0.0 \%$ & $0.0 \%$ & $0.0 \%$ & $0.0 \%$ & & $0.0 \%$ & $0.0 \%$ & $0.0 \%$ & $0.0 \%$ & $6 \%$ & $12 \%$ & $34 \%$ & $30 \%$ \\
\hline \multirow[t]{2}{*}{$\mathrm{C}$} & 0 & 0 & 0 & 0 & 0 & 24 & & 0 & 2 & 13 & 27 & 22 & 34 & 14 & 4 \\
\hline & $0.0 \%$ & $0.0 \%$ & $0.0 \%$ & $0.0 \%$ & $0.0 \%$ & $48 \%$ & & $0.0 \%$ & $4 \%$ & $26 \%$ & $54 \%$ & $44 \%$ & $68 \%$ & $28 \%$ & $8 \%$ \\
\hline \multirow[t]{2}{*}{$\mathrm{D}$} & 8 & 8 & 5 & 10 & 10 & 25 & & 24 & 33 & 30 & 24 & 25 & 10 & 4 & 4 \\
\hline & $16 \%$ & $16.0 \%$ & $10 \%$ & $20 \%$ & $20 \%$ & $50 \%$ & & $48 \%$ & $66 \%$ & $60 \%$ & $48 \%$ & $50 \%$ & $20 \%$ & $8 \%$ & $8 \%$ \\
\hline \multirow[t]{2}{*}{$\mathrm{E}$} & 18 & 18 & 34 & 34 & 34 & 1 & & 22 & 15 & 7 & 0 & 0 & 0 & 0 & 0 \\
\hline & $36 \%$ & $36.0 \%$ & $68 \%$ & $68 \%$ & $68 \%$ & $2 \%$ & & $44 \%$ & $30 \%$ & $14 \%$ & $0.0 \%$ & $0.0 \%$ & $0.0 \%$ & $0.0 \%$ & $0.0 \%$ \\
\hline \multirow[t]{2}{*}{ F } & 24 & 24 & 11 & 6 & 6 & 0 & & 4 & 0 & 0 & 0 & 0 & 0 & 0 & 0 \\
\hline & $48 \%$ & $48.0 \%$ & $22 \%$ & $12 \%$ & $12 \%$ & $0.0 \%$ & & $8 \%$ & $0.0 \%$ & $0.0 \%$ & $0.0 \%$ & $0.0 \%$ & $0.0 \%$ & $0.0 \%$ & $0.0 \%$ \\
\hline \multicolumn{16}{|c|}{ Key: Six-Point Breast Engorgement Scale } \\
\hline A & \multicolumn{6}{|c|}{ Soft, no changes in the breast } & $\mathrm{D}$ & \multicolumn{6}{|c|}{ Firm, beginning tenderness in breast } & & \\
\hline B & \multicolumn{6}{|c|}{ Slight changes in the breast } & $\mathrm{E}$ & \multicolumn{4}{|c|}{ Firm, tender } & & & & \\
\hline $\mathrm{C}$ & \multicolumn{4}{|c|}{ Firm, no tender breast } & & & $\mathrm{F}$ & \multicolumn{4}{|c|}{ Very firm, very hard } & & & & \\
\hline
\end{tabular}

Note. $\mathrm{X}^{2}=499.5$ and $590.01 ; p$-value $=.001$ and $<.001$

Table 4. Longitudinal pain score in Group 1 (warm compresses) and Group 2 (chilled cabbage leaves)

\begin{tabular}{|c|c|c|c|c|c|c|c|c|c|c|c|c|c|c|}
\hline \multirow{3}{*}{$\begin{array}{l}\text { Pain } \\
\text { degree }\end{array}$} & \multicolumn{14}{|c|}{ Application } \\
\hline & \multicolumn{2}{|c|}{1} & \multicolumn{2}{|c|}{2} & \multicolumn{2}{|c|}{3} & \multicolumn{2}{|c|}{4} & \multicolumn{2}{|c|}{5} & \multicolumn{2}{|c|}{6} & \multicolumn{2}{|c|}{7} \\
\hline & G1 & G2 & G1 & G2 & G1 & G2 & G1 & G2 & G1 & G2 & G1 & G2 & G1 & G2 \\
\hline Mean & $9.06 \pm$ & $9.06 \pm$ & $8.68 \pm$ & $8.26 \pm$ & $8.14 \pm$ & $7.32 \pm$ & $7.62 \pm$ & $6.96 \pm$ & $6.16 \pm$ & $5.56 \pm$ & $5.22 \pm$ & $4.66 \pm$ & $2.62 \pm$ & $1.86 \pm$ \\
\hline $\pm S D$ & 1.15 & 1.15 & 1.09 & 1.25 & 1.16 & 1.18 & 1.23 & 0.98 & 1.2 & 1.03 & 1.2 & 1.2 & 1.85 & 1.97 \\
\hline SER & 0.162 & 0.16 & 0.155 & 0.143 & 0.164 & 0.147 & 0.174 & 0.134 & 0.17 & 0.148 & 0.17 & 0.15 & 0.26 & 0.27 \\
\hline \multirow{6}{*}{$p$-value } & & & .14 & .032 & .001 & .001 & .001 & .001 & .001 & .001 & .001 & .001 & .001 & .001 \\
\hline & & & & & .037 & .006 & .001 & .001 & .001 & .001 & .001 & .001 & .001 & .001 \\
\hline & & & & & & & .045 & .017 & .001 & .001 & .001 & .001 & .001 & .001 \\
\hline & & & & & & & & & .001 & .001 & .001 & .001 & .001 & .001 \\
\hline & & & & & & & & & & & .001 & .001 & .001 & .001 \\
\hline & & & & & & & & & & & .001 & .001 & .001 & .001 \\
\hline
\end{tabular}

Note. Application $0=$ baseline; $\mathrm{n}=50$ participants

Table 4 shows pain scores at various points of application before and after the intervention including standard deviation $(S D)$ and standard error value (SER) data. It can be seen that there is a highly statistically significant difference regarding pain scores before and after the intervention $(p \leq .001)$. In addition, there is great improvement in the mean score after the application of warm compresses and chilled cabbage leaves compared to before the application through the six times of application compared to baseline and as obseved the improvement was high within chilled cabbage leaves as compared to warm compresses (Mean $\pm S D$ : $9.06 \pm 1.15$, $8.26 \pm 1.25,7.32 \pm 1.18,6.96 \pm 0.98,5.56 \pm 1.03,4.66 \pm$ $1.2,1.86 \pm 1.97$, respectively).

Published by Sciedu Press

Table 5 compares the pre- and post-intervention scores for breast engorgement in both groups. It can be seen that there is a highly statistically significant difference regarding the pre- and post-intervention scores for breast engorgement when comparing warm compresses application to chilled cabbage leaves. The improvement was higher in group 2 when compered to group 1 , and improvement was observed from the second to sixth and final applications $(p=.04, .033$, $.002, .02, .007$, respectively).

Regarding the pre- and post-intervention scores of pain in both groups, as shown in Table 6 , the mean of pain scores was improved in the chilled cabbage leaves than in the warm 
compresses group, with a highly statistically significant dif- .001 , respectively).

ference. Improvement was observed consistently from the

second to the sixth application $(p=.043, .028, .019, .008$,

Table 5. Comparison of longitudinal breast engorgement scores among the study groups

\begin{tabular}{|c|c|c|c|c|c|c|c|c|}
\hline \multirow{2}{*}{ Application } & \multirow{2}{*}{$\begin{array}{c}\text { Six-Point Breast } \\
\text { Engorgement Scale }\end{array}$} & \multicolumn{2}{|c|}{ Group $1(n=50)$} & & \multicolumn{2}{|c|}{ Group $2(n=50)$} & \multirow{2}{*}{$\chi^{2}$} & \multirow{2}{*}{$p$-value } \\
\hline & & No. & $\%$ & & No & $\%$ & & \\
\hline \multirow{6}{*}{0} & $\mathrm{~A}$ & 0 & 0 & & 0 & 0 & --- & 1 \\
\hline & B & 0 & 0 & & 0 & 0 & & \\
\hline & $\mathrm{C}$ & 0 & 0 & & 0 & 0 & & \\
\hline & $\mathrm{D}$ & 8 & $16.0 \%$ & & 8 & $16.0 \%$ & & \\
\hline & $\mathrm{E}$ & 18 & $36.0 \%$ & & 18 & $36.0 \%$ & & \\
\hline & $\mathrm{F}$ & 24 & $48.0 \%$ & & 24 & $48.0 \%$ & & \\
\hline \multirow{6}{*}{1} & A & 0 & 0 & & 0 & 0 & 6.2 & 0.18 \\
\hline & B & 0 & 0 & & 0 & 0 & & \\
\hline & $\mathrm{C}$ & 0 & 0 & & 0 & 0 & & \\
\hline & $\mathrm{D}$ & 10 & $20 \%$ & & 5 & $10 \%$ & & \\
\hline & $\mathrm{E}$ & 34 & $68 \%$ & & 34 & $68 \%$ & & \\
\hline & $\mathrm{F}$ & 6 & $12 \%$ & & 11 & $22 \%$ & & \\
\hline \multirow{6}{*}{2} & A & 0 & 0 & & 0 & 0 & 7.54 & 0.04 \\
\hline & B & 0 & 0 & & 0 & 0 & & \\
\hline & $\mathrm{C}$ & 24 & $48 \%$ & & 0 & 0 & & \\
\hline & $\mathrm{D}$ & 25 & $50 \%$ & & 10 & 20 & & \\
\hline & $\mathrm{E}$ & 1 & $2 \%$ & & 36 & $72 \%$ & & \\
\hline & $\mathrm{F}$ & 0 & 0 & & 4 & $8 \%$ & & \\
\hline \multirow{6}{*}{3} & A & 0 & 0 & & 0 & 0 & 8.75 & 0.033 \\
\hline & B & 0 & 0 & & 0 & 0 & & \\
\hline & $\mathrm{C}$ & 2 & $4 \%$ & & 0 & 0 & & \\
\hline & $\mathrm{D}$ & 33 & $66 \%$ & & 24 & $48 \%$ & & \\
\hline & $\mathrm{E}$ & 15 & $30 \%$ & & 22 & $44 \%$ & & \\
\hline & $\mathrm{F}$ & 0 & 0 & & 4 & $8 \%$ & & \\
\hline \multirow{6}{*}{4} & A & 0 & 0 & & 0 & 0 & 12.1 & 0.002 \\
\hline & B & 0 & 0 & & 0 & 0 & & \\
\hline & $\mathrm{C}$ & 13 & $26 \%$ & & 26 & $54 \%$ & & \\
\hline & $\mathrm{D}$ & 30 & $60 \%$ & & 24 & $48 \%$ & & \\
\hline & $\mathrm{E}$ & 7 & $14 \%$ & & 0 & 0 & & \\
\hline & $\mathrm{F}$ & 0 & 0 & & 0 & 0 & & \\
\hline \multirow{6}{*}{5} & A & 0 & 0 & & 0 & 0 & 9.2 & 0.02 \\
\hline & B & 3 & $6 \%$ & & 6 & $12 \%$ & & \\
\hline & $\mathrm{C}$ & 22 & $44 \%$ & & 34 & $68 \%$ & & \\
\hline & $\mathrm{D}$ & 25 & $50 \%$ & & 10 & $20 \%$ & & \\
\hline & $\mathrm{E}$ & 0 & 0 & & 0 & 0 & & \\
\hline & $\mathrm{F}$ & 0 & 0 & & 0 & 0 & & \\
\hline \multirow{6}{*}{6} & A & 15 & $30 \%$ & & 27 & $54 \%$ & 10.1 & 0.007 \\
\hline & B & 17 & $34 \%$ & & 15 & $30 \%$ & & \\
\hline & $\mathrm{C}$ & 14 & $28 \%$ & & 4 & $8 \%$ & & \\
\hline & $\mathrm{D}$ & 4 & $8 \%$ & & 4 & $8 \%$ & & \\
\hline & E & 0 & 0 & & 0 & 0 & & \\
\hline & $\mathrm{F}$ & 0 & 0 & & 0 & 0 & & \\
\hline \multicolumn{9}{|c|}{ Key: Six-Point Breast Engorgement Scale } \\
\hline Sot & \multicolumn{2}{|c|}{ Soft, no changes in the breast } & & $\mathrm{D}$ & \multicolumn{3}{|c|}{ Firm, beginning tenderness in breast } & \\
\hline Sli & \multicolumn{2}{|c|}{ Slight changes in the breast } & & $\mathrm{E}$ & \multicolumn{3}{|c|}{ Firm, tender } & \\
\hline Fir & \multicolumn{2}{|c|}{ Firm, no tender breast } & & $\mathrm{F}$ & \multicolumn{3}{|c|}{ Very firm, very hard } & \\
\hline
\end{tabular}


Table 6. Comparison of longitudinal pain scores among the study groups

\begin{tabular}{lcccc}
\hline Pain Degree & $\begin{array}{c}\text { Group 1 } \\
\text { (warm compresses) }\end{array}$ & $\begin{array}{c}\text { Group 2 } \\
\text { (chilled cabbage leaves) }\end{array}$ & $\boldsymbol{t}$-test & $\boldsymbol{p}$-value \\
\hline Before intervention & $9.06 \pm 1.15$ & $9.06 \pm 1.15$ & 0 & 1 \\
Mean $\pm S D$ & 0.162 & 0.16 & & \\
SER & $6-10$ & $6-10$ & & \\
After first application & $8.68 \pm 1.09$ & $8.26 \pm 1.25$ & 0.66 & .5 \\
Mean $\pm S D$ & 0.155 & 0.143 & & \\
SER & $6-10$ & $6-10$ & & \\
After second application & $8.14 \pm 1.16$ & $7.32 \pm 1.18$ & .043 \\
Mean $\pm S D$ & 0.164 & 0.147 & & \\
SER & $6-10$ & $6-10$ & & .028 \\
After third application & $7.62 \pm 1.23$ & $6.96 \pm 0.98$ & \\
Mean $\pm S D$ & 0.174 & 0.134 & 3.52 & \\
SER & $6-10$ & $6-9$ & & .019 \\
After fourth application & $6.16 \pm 1.2$ & $5.56 \pm 1.03$ & & \\
Mean $\pm S D$ & 0.17 & 0.148 & 4.35 & \\
SER & $4-8$ & $4-7$ & & \\
After fifth application & $5.22 \pm 1.2$ & $4.66 \pm 1.2$ & & \\
Mean $\pm S D$ & 0.17 & 0.15 & 6.34 & \\
SER & $2-7$ & $2-7$ & & \\
After sixth application & $2.62 \pm 1.85$ & $1.86 \pm 1.97$ & \\
Mean $\pm S D$ & 0.26 & 0.27 & & \\
SER & $0-7$ & $0-7$ & & \\
\hline
\end{tabular}

\section{DISCUSSION}

Breast engorgement is the overfilling of the breasts with milk leading to swollen, hard and painful breasts. Breast engorgement may make it difficult for women to breastfeed. It may lead to many complications such as inflammation of the breasts, infection and sore nipples. So far, consistent evidence for effective forms of treatment is lacking. ${ }^{[4,5,17,18]}$ The majority of the of the study participants were aged 29-32, and nearly two-thirds of total sample were highly educated, similar to the participants studied by El-Saidy and Abou Shady. ${ }^{[19]}$ Most women in the current study were primiparous. The two studied groups were homogeneous with regard to engorgement level of breast and pain before the treatment. After the treatment both methods (i.e., warm compresses application and chilled cabbage leaves) were demonstrated to be effective in decreasing breast engorgement and pain in postnatal mothers but the chilled cabbage leaves were more effective when compared to warm compresses. In the same line of this finding was the study which carried out by El-Saidy and Abou Shady ${ }^{[19]}$ who studied the effects of two different nursing approaches on the reduction of breast engorgement among postnatal women and found that chilled cabbage leaves are effective for relieving breast engorgement than warm compresses application.

The current study demonstrated a highly statistically significance difference in pain scores and engorgement after

Published by Sciedu Press application of warm compresses application, affirming previous findings that warm compresses are effective to relieve breast engorgement. ${ }^{[6,19]} \mathrm{A}$ similar quasi-experimental study by Ruba ${ }^{[20]}$ on 24 postnatal mothers found that warm compresses application was effective in relieving of breast engorgement and pain.

Regarding the scores of breast engorgement and pain within group 2, the mean score of pain decreased by the sixth application from 9.06 at baseline to 1.86. Great improvement was observed in the scores of engorgement and pain after the intervention. Thus this study corroborates the findings ${ }^{[21,22]}$ which concluded that chilled cabbage leaves application reduced pain associated with breast engorgement, due to promoting vasodilatation and circulation, and increasing the milk produced by the breasts, with commensurately increased duration of breastfeeding. Additionally, Joy and Kharde $^{[22]}$ evaluated the effectiveness of chilled cabbage leaves' application for relief of breast engorgement among postnatal mothers, and found that chilled cabbage leaves application was effective in reducing pain and severity of breast engorgement.

Regarding to indicators and scores of breast engorgement, the current study demonstrated that $48 \%$ of the participants recorded firm and tender breasts at baseline (level 6 of engorgement), and there was a highly statistically significant 
difference between the two groups $(p<.0001)$. Improvement was observed in both groups, but the improvement in the engorgement was high in chilled cabbage leaves than warm compresses group. Additionally, the current study illustrated that the mean pain score for the chilled cabbage leaves group reduced from $9.06 \pm 1.15$ before the intervention to 1.86 \pm 1.97 subsequently, compared to the warm compresses group's pain score reduction from $9.06 \pm 1.15$ to $2.62 \pm$ 1.85 over the same period.

It is supported by the findings ${ }^{[23]}$ of who discussed research studies to determine the effects of several interventions to relieve symptoms of breast engorgement among breastfeeding women, and found that chilled cabbage leaves were effective in the treatment of this painful condition. They also reported that chilled cabbage leaves were preferred by the lactating mothers. The obvious advantage of using chilled cabbage leaves is that it is a low cost and convenient method compared to other medical regimens, which patients can easily undertake and adopt in hospital settings and at home. ${ }^{[21,24,25]}$

Arora et al. ${ }^{[26]}$ conducted a similar comparative study and found that topical use of alternating warm compresses and chilled cabbage leaves were both effective in the treatment of breast engorgement, but that warm compresses were more effective than chilled cabbage leaves. Furthermore, Reiter $^{[27]}$ found that there was no difference in breast discomfort among mothers using chilled cabbage leaves at room temperature when compared with chilled cabbage leaves. Additionally, Folk traditions are commonly communicated in breastfeeding education. The fact that experienced practitioners are promoting the use of traditional methods like use of cabbage leaves suggests that further research is necessary to prove the efficacy of methods whose success previously has been anecdotal. ${ }^{[28-30]}$

\section{Conclusions}

According to the current findings, the present study concluded that chilled cabbage leaves application is more effective than warm compresses application to relieve breast engorgement and pain. This proved the research hypothesis which is chilled cabbage leaves is more effective than warm compresses application to relieve breast engorgement and pain among breastfeeding mothers.

\section{Recommendations}

According to the study findings, the following recommendations are proposed:

- Nurses should educate the postnatal mothers about the use of chilled cabbage leaves for managing breast engorgement in their discharge plan.

- Mothers should be advised also to apply chilled cabbage leaves and warm compresses as a home remedy to relieve engorgement and pain postnatally.

- This plan of care can also be used when the mothers are planning to wean babies from the breast completely.

- Further studies are recommended in this area in order to expand the evidence based approaches on management of breast engorgement.

\section{Conflicts of InTEREST Disclosure}

The authors declare they have no conflicts of interest.

\section{REFERENCES}

[1] Davidson MR, London ML, Ladewig PA. OLD's Maternal-Newborn Nursing \& Woman's Health, 9 th ed. Julie Levin Alexander, United States of America; 2014; 94 p.

[2] Arora S, Vatsa M, Dadhwal V. A Comparison of Cabbage Leaves vs. Hot and Cold Compresses in the Treatment of Breast Engorgement, Indian Journal of Community Medicine, official publication of Indian Association of Preventive \& Social Medicine. 2008; 33(3): 160-2. PMid: 19876476. https ://doi .org/10.4103/0970-021 8.42053

[3] Gagandeep, Sagar N, Mamta, et al. Efficacy of cabbage leaves in relief of breast engorgement among postnatal mothers. International Journal of Nursing Education. 2013; 5(2): 76-79. https: //doi.org/10.5958/j.0974-9357.5.2.068

[4] Finer LB, Zolna MR. The commitment of Breast Feeding in the United States, 2001-2008. American Journal of Public Health. 2014; 104(1): 43-48. PMid: 24354819. https://doi.org/10.2105/AJ PH. 2013.301416

[5] Mangesi L, Zakarija-Grkovic I. Treatments for breast engorgement during lactation. Cochrane Database of Systematic Reviews. 2016. PMid: 27351423. https://doi.org/10.1002/14651858.CD0 06946 .pub3

[6] Disha A, Rana A, Singh A, et al. Effect of chilled cabbage leaves vs. hot compression on breast engorgement among post-natal mothers admitted in a tertiary care hospital. Nursing and Midwifery Research Journal. 2015; 11(1): 24-32.

[7] Thomas A, Chhugani M, Thokchom S. A Quasi-experimental Study to Assess the Effectiveness of Chilled Cabbage Leaves on Breast Engorgement among Postnatal Mothers Admitted in a Selected Hospital of Delhi. International Journal of Nursing and Midwifery Research. 2017; 4(1). https ://doi.org/10.24321/2455.9318.201702

[8] Nanthini R, Bhuvaneswari G. A study to Assess the Effectiveness of Cold Cabbage Leaves Vs Hot Water Application on Breast Engorgement among Postnatal Mothers in Selected Hospital, Chennai, International Journal of Science and Research (IJSR). 2013(4): 9.

[9] Prashanth C. Effectiveness of cabbage leaves application on breast engorgement. Indian Journal of Applied Research. Dec 2014; 4(12): 472-74. 
[10] Sharma P. A Study to Assess Knowledge of Postnatal Mothers Regarding Breast Engorgement. International Journal of Nursing Education. 2013; 5(2): 130-132. https://doi.org/10.5958/j.09 $74-9357.5 .2 .079$

[11] Williams, Breast feeding and Engorgement, Obstetrics, 24th ed. McGraw-Hill Professional; 2014. Chapter 37. ISBN 9780071798938.

[12] Guilberta ER, Brownb JP, Kaunitzc AM, et al. The use of Cabbage compress on reduce Breast Engorgement. 2012; 79(3): 167-177. Available from: http://www.sciencedirect.com/science/ar ticle/pii/S0010782408005192

[13] Ward S, Hisley S, Kennedy A. maternal and child nursing care, optimizing outcomes for mothers, children and families. 2nd ed. FA Davis Company; 2016. 555-604 p.

[14] World health organization. Management of breast conditions and other breastfeeding difficulties. 2009. Available from: https : //ww w.ncbi.nlm.nih.gov/books/NBK148955/

[15] Hill PD, Humenick SS. The occurrence of breast engorgement, Journal of Human Lactation. 1994; 10(2): 79-86. PMid: 7619260. https://doi.org/10.1177/089033449401000212

[16] Gift AG. Validation of a vertical visual analogue scale as a measure of clinical dyspnea. Rehabilitation Nursing. 1989; 14(6): 323-325. PMid: 2813949. https ://doi.org/10.1002/j .2048-7940.19 89.tb01129.x

[17] Resmy V, Nalini S, Sumath G. Effect of Lukewarm Water Compress On Prevention Of Nipple Pain and Breast Engorgement among Primiparous At A Selected Hospital In Chennai. Journal of Science. 2014; 4(10): 620-624.

[18] Mangesi L, Dowswell T. Treatments for breast engorgement during lactation (Review). The Cochrane Collaboration. Published by John Wiley \& Sons, Ltd.; 2010. https ://doi.org/10.1002/146518 58. CD006946.pub2

[19] El-Saidy T, Aboushady R. Effect of two different nursing care approaches on reduction of breast engorgement among postnatal women. Journal of Nursing Education and Practice. 2016; 6(9): 1826. https://doi.org/10.5430/jnep.v6n9p18

[20] Ruba A. Effectiveness of cabbage leaf application to relieve breast engorgement. Nightingale Nursing Time's Journals of India. 2009; 5(9): 48-51.
[21] Wong B, Serena K, Hegney, G. The effectiveness of cabbage leaf application (treatment) on pain and hardness in breast engorgement and its effect on the duration of breastfeeding. JBI Library of Systematic Reviews. 2012; 10(20): 1185-1213. PMid: 27820535. https://doi.org/10.11124/jbisrir-2012-58

[22] Joy J, Kharde SN. A study to evaluate the effectiveness of chilled cabbage leaves application for relief of breast engorgement in volunteered postnatal mothers who are admitted in maternity ward of selected hospital in Belgaum. International Journal of Biological \& Medical Research. 2016; 7(3): 5655-5659.

[23] Saini P, Radha S. Cabbage Leaves and Breast Engorgement. Indian Journal of Public Health. 2014; 58(4): 291-292. PMid: 25491528. https://doi.org/10.4103/0019-557X.146309

[24] Witt A, Bolman M, Kredit S, et al. Therapeutic breast massage in lactation for the management of engorgement, plugged ducts, and mastitis. J Hum Lact. 2016; 32(1): 123-131. PMid: 26644422. https://doi.org/10.1177/0890334415619439

[25] Najem B, Dhia Al-Deen L. Breast Feeding Problems in Primipara Mothers in Early Postnatal Period. Iraqi J. Comm. Med. 2011; 24(3).

[26] Arora S, Vatsa M, Dadhwal V. Cabbage leaves vs. hot and cold compresses in the treatment of breast engorgement. Nursing Journal of India. 2009; 100(3): 52. PMid: 19876476. https://doi.org/10 $.4103 / 0970-0218.42053$

[27] Reiter M, Schuster D. Effect of cabbage leaves extract on breast engorgement. J Human Lactation. 2011; 14(3): 231-236. PMid: 10205435. https://doi.org/10.1177/089033449801400312

[28] Motee A, Ramasawmy D, Pugo-Gunsam P, et al. An assessment of the breastfeeding practices and infant feeding pattern among mothers in Mauritius. Journal of Nutrition and Metabolism. 2013. PMid: 23864943. https://doi .org/10.1155/2013/243852

[29] Czapla CH, Schaffir JO. Survey of Lactation Instructors on Folk Traditions in Breastfeeding. Breastfeeding Medicine. 2012; 7(4): 230-3. PMid: 22424468. https://doi.org/10.1089/bfm. 2011.0054

[30] Lee WT, Lui SS, Chan V, et al. A population-based survey on infant feeding practice (0-2 years) in Hong Kong: Breastfeeding rate and patterns among 3,161 infants below 6 months old. Asia Pac J Clin Nutr. 2006; 15(3): 377-87. 